\title{
Psychiatric training and the Calman reforms
}

\section{Survey of third year senior house officers}

\author{
Seonaid McCallum, Lisa McGilvray, Peter Bennie and Sue Whyte
}

\begin{abstract}
Aims and method All third year senior house officers (SHOs) training in psychiatry in scotland were canvassed by a postal questionnaire. They were asked about their views on training and the impact of the Calman reforms in psychiatry.

Results Results showed that $33 \%$ of trainees were not receiving one hour of consultant supervision per week. The quality of teaching in day release programmes was rated as average or poor by $75 \%$. Three-quarters had not seen a copy of $A$ Guide to Specialist Registrar Training, but had a good knowledge of the changes it proposed. Most were satisfied with their clinical training but expressed concerns about the Calman reforms.

Clinical implications The loss of the registrar grade has extended the time trainees spend as $\mathrm{SHO}$ and there was concern that there would be a loss of breadth of training. We intend to repeat the survey in mid-1999, by which time the Calman changes should be fully operational in psychiatry.
\end{abstract}

The term 'lost tribes' was coined to describe the senior house officer (SHO) grade (Dillner, 1993). It stems from the problems many hospital specialities face balancing service with training in the SHO posts. There has been considerable analysis and upgrading of the pre-registration house officer grade and higher specialist training grade. Improvements have emanated from the recommendations of two documents. The New Doctor (General Medical Council, 1997) and the Calman Report - Hospital Doctors: Training for the Future (Department of Health, 1993). We need to ask how the SHO grade doctors will be affected by these changes.

Psychiatry adopted a unique approach to the implementation of the Calman report. All other specialities created the new grade of specialist registrar (SpR) by amalgamating the registrar and senior registrar grades. By contrast psychiatry created the new grade out of the previous senior registrar grade with the same educational entry criteria. This caused minimal change for the post-membership trainees (Caldicott, 1993).
However, the abolition of the registrar grade and the extension of SHO training to four or more years represents a major change in status for junior trainees in psychiatry. It is these changes that are of interest for this study.

A survey was conducted throughout June and July 1997 of all third year SHOs in psychiatry in Scotland. These represented the first cohort of junior psychiatrists to reach this stage of their training since the introduction of the Calman reforms. Our objectives were to obtain an overview of the SHOs' experience of psychiatric training and their perceptions of the effects of the introduction of the SpR grade to psychiatry in Scotland. There have been previous surveys of trainees' opinions of their training (Beats et al, 1992) but this study is the first to address the impact of the Calman reforms.

\section{The study}

The study was aimed at all year three SHOs training in psychiatry throughout Scotland. This involved hospitals in four regions with different numbers of SHOs in each: West of Scotland (8), South-East of Scotland (12), Tayside (4) and Grampian (4). There was an overall response rate of $24(85 \%)$. A questionnaire was designed for the study and a copy is available on request. Those who failed to reply the first time were sent a follow-up letter with a copy of the initial questionnaire.

A pilot study was conducted using a sample of year three SHOs training in psychiatry in Newcastle $(n=15)$. The pilot study could not have taken place in Scotland because of the small numbers of SHOs available for the final study. After the pilot small changes were made to the questionnaire.

The questions asked covered three main areas: medical experience, training and the Calman reforms. There were 14 males and 10 females; there were no flexible trainees. 


\section{Findings}

\section{Medical experience}

For three-quarters of the SHOs there was a substantial time difference between the date they completed their house jobs and when they started training in psychiatry (see Fig. 1 for details). In this time the SHOs had experience in 11 different specialities, the most common being accident and emergency (11), general practice (10) and obstetrics and gynaecology (8). Only five SHOs had entered directly into psychiatry at the end of their pre-registration house officer year. All the doctors were either very satisfied $(15,62 \%)$ or reasonably satisfied $(9,38 \%)$ with their choice of speciality and all except one planned to remain in psychiatry.

\section{MRCPsych examination}

Our survey shows that these SHOs are committed to psychiatry, reinforced by the fact that all but one intended to sit the MRCPsych Part 2 examination in 1997 or 1998 . However, they expressed differing views on the timing of this exam. Thirteen (54\%) believed the exam should be brought forward by a reduction of the required training in psychiatry prior to their first attempt. The contrasting view that the exam should not be moved was expressed by nine (38\%), who felt they would be too inexperienced to make a confident attempt any earlier. A further concern was that trainees would have insufficient experience of some sub-specialities to make a decision about their future careers. There was no clear difference between these two groups in terms of previous experience.

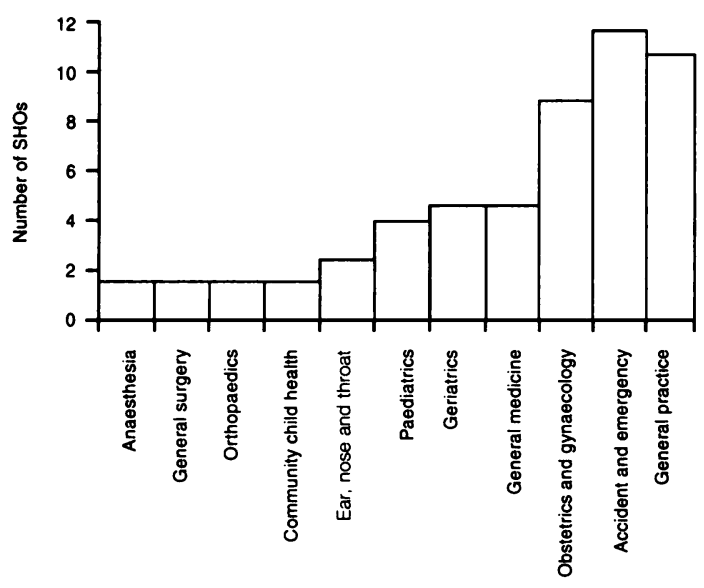

Specialities

Fig. 1. Specialities worked in since pre-registration house officer year.

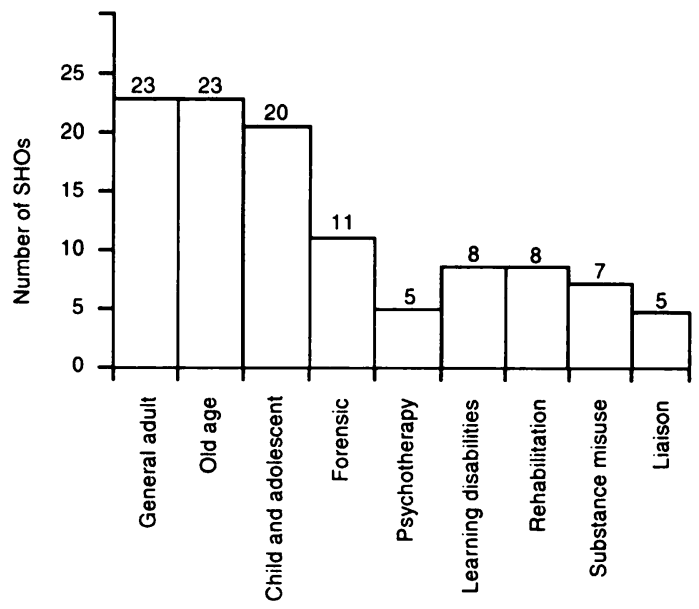

Psychiatric training

Fig. 2. Experience in specific areas of psychiatry training.

\section{Teaching and training}

All of the SHOs were enrolled on a day release programme. However, the quality of the teaching was reported as average or poor by $18(75 \%)$ and at best rated good by $6(25 \%)$. In comparison the quality of the clinical teaching was better, with 17 (71\%) saying it was very good or good and only 4 $(17 \%)$ rating it average with one saying it was poor.

The recommended one hour of supervision per week was received by $16(67 \%)$ of the SHOs. This suggests that the time devoted to supervision should be monitored to ensure consistent standards are maintained across Scotland.

The range of experience received during psychiatric training was focused in three main areas: general adult, old age and child and adolescent psychiatry. Other experience was evenly divided across a further six areas: forensic, psychotherapy, substance misuse, learning disability, rehabilitation and liaison. The length of time spent in each varied from a maximum of 18 months in general adult psychiatry to six months spent in one of the sub-specialities (see Fig. 2).

\section{Calman Report}

Three-quarters (18) of the SHOs had not seen a copy of the 'Orange Book' (NHS Executive, 1996) and only one said they had a good knowledge of the changes it proposed. This response was not surprising since copies were only officially issued to those converting to the grade. One SHO specifically stated there had been difficulties accessing information about 
Table 1. Effect of the Calman Report on the length of training

\begin{tabular}{|c|c|c|c|}
\hline & \multicolumn{3}{|c|}{ Length of training } \\
\hline & Shorter & No change & Longer \\
\hline General adult psychiatry & 7 & $\boldsymbol{9}$ & 5 \\
\hline $\begin{array}{l}\text { Flexible (part-time) } \\
\text { training }\end{array}$ & 5 & 8 & 8 \\
\hline Dual centification & 4 & 5 & 12 \\
\hline
\end{tabular}

Bold numbers indicate the correct response.

Calman because the report was not circulated to the SHOs. Similar results were found in a previous study (Evans \& Johnson, 1994).

When asked about the effects of Calman on the length of training in three specific areas of psychiatry: adult psychiatry, flexible training and dual certification, the SHOs varied in the accuracy of their knowledge (see Table 1). The majority were not aware that the time required for flexible training had been extended and similarly only a minority were aware that there would be no changes in general adult psychiatry. Twelve $(50 \%)$ were aware that training leading to dual certification would be longer than before.

Finally, these SHOs felt there would be few changes to higher training in psychiatry. Thirteen SHOs (54\%) thought there would be no changes in overall training, research opportunities, career prospects, SpR workload, job satisfaction and being a flexible trainee. However, there were areas which the SHOs thought might worsen with the implementation of the $\mathrm{SpR}$ grade. These included SHO training, opportunities for sub-speciality experience and an increase in SHO workload, see Table 2. These latter three areas would have a direct effect on the training of all SHOs in psychiatry in Scotland.

\section{Comment}

\section{General training issues}

This cohort of trainees has had a broad range of experience, both within the sub-specialities of psychiatry and for $18(75 \%)$ of the subjects, before entering psychiatry. It is a feature of psychiatric training in Scotland that so many opportunities are available for sub-speciality training.

The trainees were happy with the quality of clinical training on their rotations, but less impressed with the teaching on their day release programmes. It may be interesting to note that we found a similar result in our pilot study in Newcastle.

It is of concern that $33 \%$ of the SHOs were not receiving one hour of consultant supervision per week, the standard set by the Royal College of Psychiatrists (1997). This is consistent with previous surveys in the UK. Beats et al (1992) found a figure of $30 \%$ in a survey of senior registrars in old age psychiatry while Mulholland et al (CTC Survey of Trainee Psychiatrists, 1995, further details available from the author upon request) found a figure of $42 \%$.

\section{Implementation of the Calman Report}

Our subjects were committed to a career in psychiatry, broadly satisfied with their training to date, yet expressed negative opinions of the impact of the Calman changes. How can this paradox be explained?

One possible explanation is that they do not fully understand the effects of the introduction of the SpR grade. Few had seen the 'Orange Book', and most had a low opinion of their knowledge of Calman implementation. However, it was clear from their accompanying comments that they have had practical experience of the effects of the changes on training in psychiatry.

Table 2. Effect the introduction of the specialist registrar grade has made

\begin{tabular}{|c|c|c|c|c|c|}
\hline & Much better & Better & No change & Worse & Much worse \\
\hline Training in psychiatry overall? & 0 & 6 & 13 & 5 & 0 \\
\hline SHO training in psychiatry? & 0 & 2 & 7 & 15 & 0 \\
\hline $\begin{array}{l}\text { The opportunity to gain sub-speciality } \\
\text { experience during training in psychiatry? }\end{array}$ & 0 & 3 & 5 & 14 & 2 \\
\hline $\begin{array}{l}\text { The opportunity to pursue research projects } \\
\text { during training in psychiatry? }\end{array}$ & 0 & 3 & 13 & 7 & 1 \\
\hline Your career prospects in psychiatry? & 0 & 2 & 15 & 5 & 1 \\
\hline SHO workload in psychiatry? & 0 & 1 & 10 & 11 & 1 \\
\hline $\begin{array}{l}\text { Your perceptions of senior and specialist } \\
\text { registrar workload in psychiatry? }\end{array}$ & 1 & 3 & 10 & 10 & 0 \\
\hline Your personal job satisfaction? & 0 & 0 & 16 & 6 & 1 \\
\hline Flexible (part-time) training in psychiatry? & 0 & 8 & 8 & 3 & 1 \\
\hline
\end{tabular}


Fears about a worsening of training and workload for SHOs, fewer opportunities for subspeciality experience and lower personal job satisfaction mirror the views of trainees in other specialities. However, there are issues which are unique to psychiatry. The loss of the registrar grade and the extension of time spent as an SHO have had two effects which were commented upon by our subjects. Trainee psychiatrists now receive no recognition for their experience and commitment by means of promotion until they have spent four or more years in the speciality. A number of our respondents commented upon this situation for example, "I am saddened by the loss of the registrar grade. If still present it would perhaps be a recognition of experience rather than remaining in the SHO grade for years." This is compounded by significant financial loss for those who come into psychiatry from other specialities. These doctors are quickly stuck at the top of the SHO pay scale, while previously they would have had access to the registrar pay scale after passing Part 1 of the MRCPsych examination (Evans \& Johnson, 1994).

The results of this survey are a cause for concern. If SHOs continue to feel such discontent with the organisation of their training, then it is likely that recruitment and retention of trainees will be adversely affected. A closer focus should be applied to training in the SHO grade as well as the SpR grade, as the Calman changes continue to take effect.

\section{Further research}

Some of the respondents suggested our survey should be repeated and we intend to do this in mid-1999, by which point the Calman changes should be fully operational in psychiatry. This will allow us to differentiate between problems with transition to the SpR grade and ongoing problems with training. It would be useful, at that stage, to review trainees' views of the MRCPsych examination and the timing of this exam.

\section{Acknowledgement}

We wish to thank Dr Desmond Dunleavy from the Royal Victoria Infirmary, Newcastle upon Tyne for his assistance and permission to survey a sample of the SHOs in his region for our pilot study.

\section{References}

Beats, B., BAGLEY, G., BANKS, V., et al (1992) Higher training in old age psychiatry: a survey of senior registrars' experiences. Psychiatric Bulletin, 16, 622624.

CALDICOTT, F. (1993) Response to the Chief Medical Officer's Report on specialist training. Hospital doctors: training for the future. Psychiatric Bulletin, 17. 577-579.

DEPARTMENT OF HEALTH (1993) Hospital Doctors: Training for the Future. The Report of the Working Group on Specialist Medical Training (The Calman Report). London: Department of Health.

DILLNER, L. (1993) Senior house officers: the lost tribes. British Medical Journal, 307, 1549-1551.

Evans, M. \& JoHnSON, C. (1994) The Calman Report: does training matter to trainees? Psychiatric Bulletin, 18. 405-407.

GENERAL MEDICAL COUnCIL (1997) The New Doctor: Protecting Patients, Guiding Doctors. London: GMC.

NHS EXECUTTVE (1996) A Guide to Specialist Registrar Training. Leeds: Department of Health.

Royal College of PSYCHIATRISTs (1997) Educational Policy (Occasional Paper OP36). London: Royal College of Psychiatrists.

*Seonaid McCallum, Specialist Registrar in Psychiatry, No. 2 The Bungalows, Stirling Road, Larbert, Stirlingshire FK5 4SD; Lisa McGilvray, Educational Facilitator, Stirling Royal Infirmary NHS Trust, Stirling; Sue Whyte, Consultant Psychiatrist and Educational Co-ordinator, Greater Glasgow C and MHS, NHS Trust and Peter Bennie, Consultant Psychiatrist, Parkhead Hospital, Glasgow

${ }^{*}$ Correspondence 